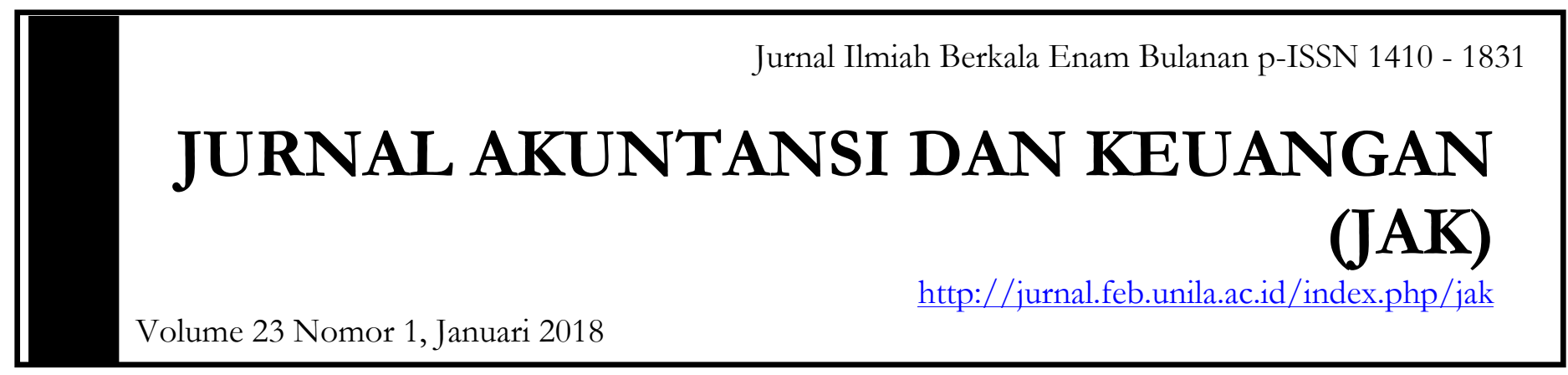

\title{
KINERJA LINGKUNGAN DAN TINGKAT PENGUNGKAPAN CSR SEBELUM DAN SESUDAH UU NO 47 TAHUN 2012 \\ Fadli Andika Putra ${ }^{1}$, Lindrianasari ${ }^{2}$ \\ ${ }^{1}$ Program Studi Akuntansi FEB Universitas Lampung \\ ${ }^{2}$ Program Studi Akuntansi FEB Universitas Lampung
}

\section{Informasi Naskah}

Update Naskah:

Dikumpulkan: 19 Sept 2017;

Diterima: 22 January 2018;

Terbit/Dicetak: 30 January 2018.

\section{Keywords:}

Environmental performance, CSR disclosure rate, Law No.47 year 2012

\begin{abstract}
Environmental performance and disclosure level of CSR to the enactment of Law No.47 year 2012 is still voluntary. This means companies are not required to disclose environmental performance in the annual report. While in 2012 has been applied new law, then with enactment of the Act environmental performance should be disclosed in the annual report. This study aims to determine how much influence Law No. 47 year 2012 can improve the environmental performance and the level of CSR dsiclosure. There are two variables in this study, ie environmental performance as measured by ISO 14001 certification and CSR disclosure rate measured by GRI4. The number of sample of this study amounted to 640 companies of all companies listed on the BEI in 2008-2015. From the results of research on environmental performance and disclosure level of CSR, positively affect the implementation of Law No.47 year 2012.
\end{abstract}




\section{A. PENDAhuluan}

Tujuan utama perusahaan dalam segi ekonomi adalah memperoleh keuntungan (profit) yang optimal. Keberadaan perusahaan tidak bisa terlepas dari lingkungan dimana perusahaan tersebut berada. Bagi perusahaan yang bergerak dibidang pemanfaatan sumber daya alam, seringkali perusahaan tersebut mengabaikan dampak-dampak sosial dan lingkungan yang terjadi karena imbas dari kegiatan perusahaan itu. Dimana dampak tersebut merusak lingkungan sekitar tempat perusahaan tersebut beroprasi seperti penggundulan hutan, polusi udara, pencemaran air karena limbah pabrik dan lain-lain.

Adanya dampak dari kegiatan perusahaan tersebut yang sangat merugikan terutama bagi masyarakat sekitar, membuat masyarakat sadar bahwasanya perusahaan dituntut agar melakukan tanggung jawab sosial yang dikenal dengan Corporate Social Responsibility (CSR). Masyarakat menginginkan kerusakan terhadap lingkungan dikendalikan sehingga dampak sosial yang timbul bisa dihindari.Pengungkapan akuntansi lingkungan (Environmental Accounting Disclosure selanjutnya disingkat dengan EAD) di Negara-Negara berkembang memang masih sangat kurang. Banyak penelitian di area Social Accounting Disclosure (selanjutnya akan disingkat dengan SAD) umumnya dan EAD pada khususnya memperlihatkan bahwa pihak perusahaan melaporkan kinerja lingkungan yang masih sangat terbatas. Kondisi ini, salah satunya dikarenakan lemahnya sangsi hukum yang berlaku di negara tersebut. Lindrianasari (2007) menemukan bahwa terdapat hubungan yang negatif antara sangsi hukum dengan pengungkapan akuntansi lingkungan yang wajib dengan penyimpangan aturan yang dilakukan oleh perusahaan. Artinya, semakin keras sangsi hukum yang berlaku di suatu negara, akan semakin mengurangi penyimpangan aturan yang telah ditetapkan oleh pihak regulator. Hal ini menunjukan bahwa sesungguhnya pihak regulator memiliki kekuatan untuk menekan pihak perusahaan dalam meminimalisasikan dampak kerusakan lingkungan yang disebabkan oleh kegiatan usaha mereka.

\section{B. LANDASAN TEORI DAN PENGEMBANGAN HIPOTESIS Teori Legitimasi}

Legitimasi dapat dianggap sebagai menyamakan persepsi atau asumsi bahwa tindakan yang dilakukan oleh suatu entitas adalah merupakan tindakan yang diinginkan, pantas ataupun sesuai dengan sistem norma, nilai, kepercayaan dan definisi yang dikembangkan secara sosial (Suchman,1995). Legitimasi dianggap penting bagi perusahaan dikarenakan legitimasi masyarakat kepada perusahaan menjadi faktor yang strategis bagi perkembangan perusahaan kedepan.

O’Donovan (2000) berpendapat legitimasi organisasi dapat dilihat sebagai sesuatu yang diberikan masyarakat kepada perusahaan dan sesuatu yang diinginkan atau dicari perusahaan dari masyarakat. Dengan demikian legitimasi memiliki manfaat untuk mendukung keberlangsungan hidup suatu perusahaan. Legitimasi merupakan sistem pengelolaan perusahaan yang berorientasi pada keberpihakan terhadap masyarakat (society), pemerintah individu dan kelompok masyarakat, Grayetal. (1996:46). Untuk itu, sebagai suatu sistem yang mengutamakan keberpihakan atau kepentingan masyarakat.

Deeganet al. (2002) menyatakan legitimasi dapat diperoleh manakala terdapat kesesuaian antara keberadaan perusahaan tidak mengganggu atau sesuai (congruent) dengan eksistensi sistem nilai yang ada dalam masyarakat dan lingkungan. Ketika terjadi pergeseran yang menuju ketidaksesuaian, maka pada saat itu legitimasi perusahaan dapat terancam.

Dasar pemikiran teori ini adalah organisasi atau perusahaan akan terus berlanjut keberadaannya jika masyarakat menyadari bahwa organisasi beroperasi untuk sistem nilai yang 
sepadan dengan sistem nilai masyarakat itu sendiri. Teori legitimasi menganjurkan perusahaan untuk meyakinkan bahwa aktivitas dan kinerjanya dapat diterima oleh masyarakat. Perusahaan menggunakan laporan tahunan mereka untuk menggambarkan kesan tanggung jawab lingkungan, sehingga mereka diterima oleh masyarakat.

\section{Pengungakapan Corporate Social Responsibitily (CSR)}

Grayetal., (2001) menyatakan bahwa CSR Disclosure merupakan suatu proses penyedia informasi yang dirancang untuk mengemukakan masalah seputar social accountability, yang mana secara khas tindakan ini dapat dipertanggungjawabkan dalam media-media seperti laporan tahunan maupun dalam bentuk iklan yang berorientasi sosial. Pengungkapan CSR merupakan pengungkapan suatu informasi mengenai aktivitas sosialyang dilakukan perusahaan yang diharapkan dapat mempengaruhi persepsi masyarakat terhadap perusahaan dan mempengaruhi kinerja keuangan perusahaan.

Menurut Chariri dan Ghozali(2007) pengungkapan dapat diartikan sebagai pemberian informasi bagi pihak-pihak yang berkepentingan terhadap informasi tersebut. Tujuan pengungkapan dikategorikan menurut Securities Exchange Commission (SEC) menjadi dua,yaitu 1) protective disclosure yang sebagai upaya perlindungan terhadap investor, dan2) informative disclosure yang bertujuan memberikan informasi yang layak kepada pengguna laporan. Pengungkapan berkaitan dengan akuntansi pertanggungjawaban sosial bertujuan untuk menyediakan informasi yang memungkinkan dilakukan evaluasi pengaruh perusahaan terhadap masyarakat. Pengaruh kegiatan ini bersifat negatif, yang menimbulkan biaya sosial pada masyarakat, atau positif yang berarti menimbulkan manfaat sosial bagi masyarakat (Yuningsih, 2001).

Terdapat dua jenis pengungkapan dalam pelaporan keuangan yang telah ditetapkan oleh badan yang memiliki otoritas dipasar modal. Yang pertama adalah pengungkapan wajib (mandatory disclosure), yaitu informasi yang harus diungkapkan oleh emiten yang diatur oleh peraturan pasar modal di suatu negara. Sedangkan yang kedua adalah pengungkapan sukarela (voluntary disclosure), yaitu pengungkapan yang dilakukan secara sukarela oleh perusahaan tanpa diharuskan oleh standar yang ada (Fitriyani, 2012). Pengungkapan sosial di Indonesia termasuk ke dalam kategori mandatory disclosure.

\section{Kinerja Lingkungan}

Kinerja lingkungan adalah kinerja perusahaan dalam menciptakan lingkungan yang baik (green) (Suratnoetal.,2006). Perusahaan memberikan perhatian terhadap lingkungan sebagai wujud tanggung jawab dan kepedulian perusahaan terhadap lingkungan. Kinerja lingkungan dapat dilakukan dengan menerapkan akuntansi lingkungan. Akuntansi lingkungan merupakan pengakuan dan integrasi dampak isu-isu lingkungan pada sistem akuntansi tradisional suatu perusahaan (Halim dan Irawan,1998). Akuntansi lingkungan tidak hanya menghitung biaya dan manfaat ekonomi perusahaan, tetapi juga memperhitungkan biaya lingkungan yang merupakan eksternalitas ekonomi negatif atau biaya-biaya yang timbul diluar pasar. Kendala yang dihadapi oleh akuntansi lingkungan adalah belum adanya standar pengukuran dan penilaian dampak aktivitas perusahaan terhadap lingkungan, sebab tidak semua biaya dan manfaat lingkungan mudah diidentifikasi dan diukur dalam ukuran moneter (HalimdanIrawan,1998).

\section{METODE PENELITIAN Populasi Dan Sampel}


Populasi adalah sejumlah unsur-unsur dimana suatu kesimpulan akan disusun. Populasi dalam penelitian ini adalah perusahaan manufaktur yang telah terdaftar di BEI (Bursa Efek Indonesia) 4 tahun sebelum dan 4 tahun sesudah ditetapkannya UU NO. 47 tahun 2012 yaitu dari tahun 2008-2015. Dipilihnya perusahaan manufaktur dimaksudkan karena industri tersebut kerat kaitanya dengan produksi langsung sehingga efek limbah yang dapat mencemari lingkungan lebih besar.

\section{Jenis Dan Sumber Data}

Jenis data yang digunakan dalam penelitian ini adalah data sekunder. Data sekunder yang berupa laporan tahunan perusahaan manufaktur yang diperoleh dari Indonesia Stock Exchange (IDX) periode 2008-2015. Sedangkan kinerja lingkungan yang diukur dengan sertifikasi ISO juga merupakan data sekunder yang diambil dari annual report perusahaan.

\section{Variabel Penelitian Dan Definisi Oprasional}

\section{Kinerja Lingkungan}

Pada penelitian ini, kinerja lingkungan perusahaan diukur dengan sertifikasi ISO 14001 yang merupakan sertifikat terhadap sistem manajemen lingkungan yang baik. Untuk pengukurannya akan digunakan dummy variable, nilai 1 akan diberikan bagi perusahaan manufaktur yang masuk dalam kategori menjalankan kinerja lingkungan yang baik dan 0 untuk perusahaan yang belum bersertifikasi ISO 14001.

\section{Tingkat Pengungkapan Corporate Social Responsibitilty (CSR)}

CSR disclosure diukur dengan menggunakan index CSR majemuk. Kategori tingkat pengungkapan CSR menggunakan standar dari GRI (global reporting initiative). GRI terdiri dari 3 fokus pengungkapan, yaitu ekomomi,lingkungan dan sosial sebagai dasar sustainability reporting (Dahlia dan Siregar,2008).

Terdapat beberapa indikator dalam GRI sebagai berikut:

1. indikator kinerja finansial

2. indikator kinerja lingkungan

3. indikator kinerja tenaga kerja

4. indikator kinerja hak asasi manusia

5. indikator kinerja sosial

6. indikator kinerja produk

Pada penelitian ini indikator yang dipakai hanya lima yaitu, kinerja finansial, kinerja tenaga kerja, kinerja hak asasi manusia, kinerja sosial, kinerja produk. Pendekatan untuk menghitung CSDI pada dasarnya mengunakan dikotomi yaitu setiap item CSR dalam instrument penelitian ini diberi nilai 1 jika diungkapkan dan 0 jika tidak diungkapkan (Haniffa et al, 2005 )Indeks pengungkapan masingmasing perusahaan kemudian dihitung dengan membagi jumlah item yang diungkapkan perusahaan dengan jumlah item yang diharapkan diungkapkan perusahaan ini konsisten dengan penelitian yang sebelumnya yang dilakukan di Indonesia (Utomo, 2000), yang dinyatakan dalan corporate social responsibility indexs (CSRI) dengan rumus sebagai berikut :

$$
C S R i j=\frac{\sum X i j}{n_{j}}
$$


CSRij :corporate social responsibility index perusahaan $\mathrm{j}$

nj : jumlah item untuk perusahaan

xXij : variable dummy, $1=$ jika item i diungkapkan, 0 jika item i tidak diungkapkan, dengan demikian, $0 \leq \mathrm{CSRI;nj \leq 1}$

\section{Metode Analisis}

Tipe penelitian ini dari sudut pandang rerangka berpikir tergolong penelitian kuantitatif. Kerangka berpikir jenis ini menguji teori-teori dengan menggunakan angka dan metode statistik dalam melakukan analisis data (Yamin dan Kurniawan, 2009). Alat uji yang digunakan dalam pengujian penelitian ini adalah paired sampel t-test. Pengujian inidigunakan pada data yang berdistribusi normal untuk menguji apakah secara ststistik terdapat perbedaan kinerja lingkungan dan tingkat pengungkapan CSR sebelum dan sesudah UU No 47 tahun 2012. Apabila data berdistribusi tidak normal maka alat analisis yang digunakan adalah wilcoxon signed rank test. Tingkat keyakinan yang digunakan dalam pengujian ini adalah 0,95 atau $\alpha=0,05$ (2-tailed).

Alat analisis yang digunakan untuk menguji perbedaan pengaruh kinerja lingkungan terhadap tingkat pengungkapan CSR sebelum dan sesudah UU No 47 tahun 2012 adalah program SPSS 16.0 dengan derajat kepercayaan sebesar $95 \%$ dan tingkat kesalahan sebesar $5 \%$. Jika probabilitas $(p$ value $)<5 \%$ maka Ha terdukung, tetapi apabila probabilitas ( $p$-value $)>5 \%$ maka Ha tidak terdukung.

Sebelum dilakukan pengujian hipotesis, dilakukan pengujian distribusi normalitas data menggunakan uji kolmogorov smirnov. Pada pengujian ini, jika data berdistribusi normal maka menggunakan alat analisis paired sample t-test yang terdapat pada menu compare means dalam SPSS, namun apabila data berdistribusi tidak normal maka alat analisis yang digunakan adalah wilcoxon signed rank test yang terdapat pada menu non parametric test dalam SPSS dengan tingkat keyakinan yakni 0,95 atau $\alpha=0,05$ (2-tailed).

\section{ANALISIS DAN PEMBAHASAN}

\section{Uji Normalitas Kinerja Lingkungan}

Hasil uji statistik non parametik kolmogorov simirnov kinerja lingkungan dapat dilihat pada tabel 1 berikut ini.

Tabel 1 Hasil One-Sample Kolmogorov-Smirnov Test Kinerja Lingkungan

\begin{tabular}{|c|c|c|c|}
\hline & ISOsebelum & ISOsetelah \\
\hline $\mathrm{N}$ & & 320 & 320 \\
\hline \multirow[t]{2}{*}{ Normal Parameters ${ }^{\mathrm{a}}$} & Mean & .21 & .44 \\
\hline & Std. Deviation & .405 & .497 \\
\hline \multirow{3}{*}{$\begin{array}{l}\text { Most Extreme } \\
\text { Differences }\end{array}$} & Absolute & .488 & .372 \\
\hline & Positive & .488 & .372 \\
\hline & Negative & -.305 & -.310 \\
\hline \multicolumn{2}{|c|}{ Kolmogorov-Smirnov Z } & 8.736 & 6.647 \\
\hline \multicolumn{2}{|l|}{ Asymp. Sig. (2-tailed) } & .000 & .000 \\
\hline
\end{tabular}

Sumber data: data output SPSS, 2017

Tabel 1 diatas merupakan hasil pengujian uji statistik non paramtrik kolmogorov simirnov, yang 
menunjukan bahwa variabel yang diujikan dalam penelitian ini yaitu Kinerja lingkungan sebelum dan setelah UU No. 47 tahun 2012 memiliki nilai signifikansi 0,000<0,05 $(\alpha=5 \%)$. Hal ini menunjukan bahwa H0 ditolak dan Kinerja lingkungan sebelum dan setelah UU No. 47 tahun 2012 terdistribusi tidak normal.

\section{Uji Normalitas Tingkat Pengungkapan CSR}

Uji normalitas diperlukan untuk mengetahui dan memastikan sebelum dilakukan uji analisis paired sampel t-test data terdistribusi normal. Namun jika data tidak terdistribusi secara normal akan digunakan uji wilxoson signed rank. Berikut ini adalalah tabel hasil pengujian statistik non parametrik kolmogorov simirnov dengan kriteria;

Hipotesis H0 ditolak bila asymptotic signifikan value $<0,05$

Hasil uji statistik non parametrik kolmogorov simirnov tingkat pengungkapan CSR sebelum dan setelah UU No. 47 tahun 2012 dapat dilihat pada tabel berikut;

Tabel 2 Hasil Uji Kolmogorov Simirnov Pengungkapan CSR

\begin{tabular}{llrr}
\hline & & CSRsebelum & CSRsetelah \\
\hline $\mathrm{N}$ & & 320 & 320 \\
Normal Parameters $^{\mathrm{a}}$ & Mean & .04979 & .22878 \\
& Std. Deviation & .030615 & .086252 \\
Most Extreme & Absolute & .257 & .065 \\
Differences & Positive & .257 & .065 \\
& Negative & -.208 & -.046 \\
Kolmogorov-Smirnov Z & 4.604 & 2.159 \\
Asymp. Sig. (2-tailed) & & .000 & .000 \\
\hline
\end{tabular}

Sumber data: data output SPSS, 2017

Tabel 2 diatas merupakan hasil pengujian uji statistik non paramtrik kolmogorov simirnov, yang menunjukan bahwa variabel yang diujikan dalam penelitian ini yaitu tingkat pengungkapan CSR sebelum dan setelah UU No. 47 tahun 2012 memiliki nilai signifikansi $0,000<0,05(\alpha=5 \%)$. Hal ini menunjukan bahwa H0 ditolak dan variabel tingkat pengungkapan CSR sebelum dan setelah UU No. 47 tahun 2012 terdistribusi tidak normal.

\section{Analisis Data}

\section{Pengujian Hipotesis Pertama}

Pengujian hipotesis ini dilakukan untuk mengetahui apakah terdapat perbedaan signifikan antara kinerja lingkungan sebelum dan setelah UU No. 47 tahun 2012, yang didefinisikan kedalam hipotesis pertama yaitu;

H1: Ada beda yang signifikan pada kinerja lingkungan sebelum dan setelah penerapan UU No. 47 tahun 2012. Output uji wilcoxon signed rank kinerja lingkungan sebelum dan setelah UU No. 47 tahun 2012 dapat ditunjukan dalam tabel 4.7 sebagai berikut. 
Tabel 3 wilcoxon signed rank test

\begin{tabular}{llrrr}
\hline & & \multicolumn{3}{r}{ Mean Rank Sum of Ranks } \\
\hline ISOsesudah - & Negative Ranks & $0^{\mathrm{a}}$ & .00 & .00 \\
ISOsebelum & Positive Ranks & $75^{\mathrm{b}}$ & 38.00 & 2850.00 \\
& Ties & $245^{\mathrm{c}}$ & & \\
& Total & 320 & & \\
\hline
\end{tabular}

Tabel 4 Test Statistics ${ }^{\mathrm{b}}$

\begin{tabular}{cc}
\hline & ISOsesudah - ISOsebelum \\
\hline $\mathrm{Z}$ & $-8.660^{\mathrm{a}}$
\end{tabular}

Asymp. Sig. (2tailed)

.000

Sumber: data output SPSS, 2017

Berdasarkan hasil uji hipotesis terhadap kinerja lingkungan dengan uji wilcoxon signed rank diatas, diketahui bahwa secara statistik signifikansi yang terlihat dari value (sig-2 tailed) sebesar 0.000 lebih kecil dari $\alpha=5 \%$ menunjukan bahwa perbedaan tersebut signifikan dah H1 diterima. Hasil pengujian tersebut dapat disimpulkan bahwa kinerja lingkungan sebelum UU No. 47 tahun 2012 jauh berbeda saat diterapkanya UU tersebut, sehingga kinerja lingkungan setelah UU No. 47 tahun 2012 lebih baik.

\section{Pengujian Hipotesis Kedua}

Pengujian hipotesis kedua ini dilakukan untuk mengetahui apakah terdapat perbedaan signifikan antara tingkat pengungkapan CSR sebelum dan setelah UU No. 47 tahun 2012, yang didefinisikan kedalam hipotesis kedua yaitu;

H2: Ada beda yang signifikan pada tingkat pengungkapan CSR sebelum dan setelah penerapan UU No. 47 tahun 2012.

Output uji wilcoxon signed rank tingkat pengungkapan CSR sebelum dan setelah UU No. 47 tahun 2012 dapat ditunjukan pada tabel berikut.

Berdasarkan hasil uji hipotesis terhadap tingkat pengungkapan CSR dengan uji wilcoxon signed rank, diketahui bahwa secara statistik signifikansi yang terlihat dari value (sig-2 tailed) sebesar 0,000 kurang dari $\alpha=5 \%(0,05)$ menunjukan bahwa perbedaan tersebut signifikan dan $\mathrm{H} 2$ diterima. Hasil pengujian tersebut dapat disimpulkan bahwa tingkat pengungkapan CSR sebelum dan sesudah penerapan UU No. 47 tahun 2012 mengalami perbedaan yang signifikan yang artinya tingkat pengungkapan CSR setelah penerapan UU No. 47 tahun 2012 lebih besar dibandingkan sebelum penerapan UU No. 47 tahun 2012.

Tabel 5 hasil pengujian wilcoxon signed rank

\begin{tabular}{llrrr}
\hline & N & Mean Rank Sum of Ranks \\
\hline CSRsesudah - & Negative Ranks & $0^{\text {a }}$ & .00 & .00 \\
CSRsebelum & Positive Ranks & $319^{\mathrm{b}}$ & 160.00 & 51040.00
\end{tabular}


Ties

Tabel 6 Test Statistics ${ }^{\mathrm{b}}$

\begin{tabular}{rr}
\hline CSRsesudah - CSRsebelum \\
\hline - $15.486^{\mathrm{a}}$
\end{tabular}

Asymp. Sig. (2tailed)

Sumber: data output SPSS, 2017.

\section{E. SIMPULAN DAN SARAN Simpulan}

Penelitian ini bertujuan untuk mengetahui apakah ada pengaruh diterapkanya UU No. 47 tahun 2012 terhadap kinerja keuangan dan tingkat pengungkapan corporate social responsibility (CSR) pada perusahaan manufaktur yang terdapat dalam Bursa Efek Indonesia (BEI) tahun 2008-2015. Berdasarkan hasil penelitian yang telah dilakukan, maka diperoleh kesimpulan sebagai berikut.

1. Hasil penelitian mengenai variabel kinerja lingkungan terdapat perbedaan yang signifikan sebelum dan setelah diterapkanya UU No. 47 tahun 2012 pada perusahaan yang menjadi sampel penelitian ini. Hal ini dapat diartikan bahwa dengan adanya UU No. 47 tahun 2012 menyebabkan kinerja lingkungan pada perusahaan manufaktur berbeda dari sebelum diterapkanya UU No. 47 tahun 2012 tersebut. Hal ini dapat disimpulkan bahwa dengan adanya campur tangan pemerintah dalam membuat undang-undang yang mengatur tentang kebijakan lingkungan dapat diterapkan dengan baik oleh perusahaan-perusahaan manufaktur yang menjadi objek penelitian ini, sehingga dampak positif dari tujuan diberlakukanya UU No. 47 tahun 2012 ini dapat dirasakan oleh semua pihak, terutama masyarakat itu sendiri.

2. Hasil penelitian mengenai tingkat pengungkapan corporate social responsibility (CSR) terdapat perbedaan signifikan tingkat pengungkapan CSR sebelum dan setelah penerapan UU No. 47 tahun 2012 pada masing-masing sampel yang menjadi objek penelitian. Hal ini dapat diartikan bahwa dengan adanya UU No. 47 tahun 2012 menyebabkan tingkat pengungkapan CSR pada perusahaan manufaktur yang diteliti jauh lebih baik, yang berarti perusahaan-perusahaan tersebut telah menjalankan kewajibanya untuk perduli terhadap lingkungan sekitar.

\section{Keterbatasan Penelitian}

Terdapat beberapa keterbatasan masalah dalam melakukan penelitian ini, yaitu;

1. Penelitian ini hanya menggunakan laporan keuangan priode pengamatan empat tahun sebelum dan empat tahun setelah diberlakukanya UU No. 47 tahun 2012. Tahun 2008-2011 merupakan tahun sebelum diterapkanya UU No. 47 tahun 2012. sedangkan penerapan UU No. 47 tahun 2012 yaitu dari tahun 2012-2015.

2. Pemilihan sampel akhir didasarkan ketersediaan data dan informasi yang disajikan dalam annual report, namun beberapa informasi tidak lengkap sehingga dikeluarkan dari sampel penelitian agar tidak menimbulkan kesalahan. 


\section{Saran}

Berdasarkan beberapa keterbatasan yang telah dipaparkan diatas, saran yang dapat diajukan untuk penelitian yang akan datang antara lain sebagai berikut.

1. Bagi peneliti selanjutnya dapat memperbanyak jumlah sampel dan tidak terbatas hanya perusahaan sektor manufaktur, dapat menggunakan seluruh sektor perusahaan yang terdapat dalam Bursa Efek Indonesia (BEI) agar lebih memadai untuk pengujian hipotesis yang ada dan diperoleh hasil yang berbeda.

2. Bagi peneliti selanjutnya penelitian bisa dikembangkan dengan nenambahkan variabel yang diteliti maupun menambahkan priode waktu sebelum dan sesudah implementasi UU No. 47 tahun 2012.

\section{REFERENSI}

Ahmad, N.N.N., dan Sulaiman, M. 2004. Environmetal Disclosures In Malaysian Annual Reports: A Legitimacy Theory Perspective. International Journal of Commerece and Management, 1444.

Astuti, Dewi dan Saptantiah Puji. 2010. Peran Internal Audit dan Komite Audit dalam Mewujudkan Good Corporate Governance. Jurnal Akuntansi Dan Sistem Teknologi Informasi, 8 (1); 1-9.

Beasley, Mark S. 1996. An Empirical Analysis of The Relation Between The Board of Director Composition and Financial Statemen Fraud. The Accounting Review, 71 (4); 443-465.

Chandra, Ferdinan Kris. 2006. Pengaruh Tindakan Supervisi Terhadap Kinerja Auditor Internal dengan Motivasi Kerja Sebagai Variabel Intervening. (http://eprints.undip.ac.id/15599)

Dahlia, D.,\& Siregar.,S.V. 2008. Pengaruh Corporate Sosial Responsibility Terhadap Kinerja Perusahaan (Study Empiris Pada Perusahan yang Tercatat Dalam Bursa Efek Indonesia Tahun 2005 dan 2006). Simposium Nasional Akuntansi XI, Pontianak.

Effendy, Muhamad Arief. 2005. Peran Komite Audit dalam Meningkatkan Kinerja Perusahaan. Jurnal Akuntansi Pemerintah. 1 (1);51-57.

Fitriyani. 2012. Keterkaitan Kinerja Lingkungan, Pengungkapan Corporate Social Responsibility (CSR), dan Kinerja Financial. Http://eprints.undip.ac.id/35522/skripsi 30.pdf

Fr.Reni dan Retno Anggraini. 2006. Pengungkapan Sosial dan Faktor-faktor Yang Mempengaruhi Pengungkapan Informasi Sosial dalam Laporan Keuangan Tahunan (Study Empiris Pada Perusahaan-Perusahaan yang Terdaftar Bursa Efek Jakarta). Simposium Nasional Akuntansi IX Padang

Ganyowati, Evi \& Nugroho, Dhinar adi. 2009. Pengaruh Independen dan Dewan Komite Audit Terhadap Pengurangan Asimetri Informasi Disekitar Pengumuman Laba. Jurnal Siasat Bisnis, 13 (3); 253-265 
Gray R., Javad M., David M.P., \& Donald S. 2001. Sosial And Environmental Disclosure And Corporate Characteristic: A Research Note And Extension. Jurnal Of Business Finance And Accounting, 44 (5); 327-356

Halim, Abdul, dan Arif Surya Irawan. 1998. Perspektif Akuntansi Lingkungan, Suatu Tinjauan Teoritis Mengenai Isu Dampak Lingkungan Terhadap Akuntansi. Jurnal Ekonomi Dan Bisnis Indonesia, 33 (3).

Ihsan, Arfan. 2008. Akuntansi Lingkungan dan Pengungkapannya. Yogyakarta; Graha Ilmu

Jogiyanto. 2000. Sistem Informasi Berbasis Computer Konsep Dasar dan Komponen. Edisi Kedua. Yogyakarta: BPFE

Hasibuan, Malayu. 2001. Manajemen Sumber Daya Manusia: Pengertian Dasar, Pengertian, dan Masalah. Jakarta: PT. Toko Gunung Agung

Ja'far,S, Muhamad dan Arifah, Dista Amalia, 2006. Pengaruh Dorongan Manajemen Lingkungan, Manajemen Lingkungan Proaktif dan Kinerja Lingkungan Public Environmental Reporting. Simposium Nasional Akuntansi IX Padang

Kirana, Rosita Candra. 2009. Studi Perbandingan Pengaturan Tentang CSR Dibeberapa Negara dalam Upaya Perwujudan Prinsip GCG”.

Http://digilib.uns.ac.id/pengguna.php?mn=detail\&d id=1583

Lindrianasari. 2007. Hubungan Antara Kinerja Lingkungan dan Kualitas Pengungkapan Lingkungan dengan Kinerja Ekonomi Perusahaan di Indonesia. Jurnal akuntansi dan auditing Indonesia, $11(2): 159-166$

Muamal, Khairunisa. 2011. Peran Komite Audit Terhadap Kinerja Manajemen Rumah Sakit Umum Daerah. http://eprints.undip.ac.id/33131/1/skripsi_17

Mulyadi dan Kanaka Puradireja. 1998. Auditing Buku 1. Jakarta: Salemba Empat

Nasution, Manahan. 2003. Sekilas Tentang Internal Auditor. Jakarta: Salemba Empat.

Rakheimah A.N \& Agustina D. 2009. Pengaruh Kinerja Lingkungan Terhadap CSR Disclosure dan Kinerja Finansial Perusahaan Manufaktur Yang Terdaftar Di Bursa Efek Indonesia. Simposium Nasional Indonesia 12. Palembang

Rahmawati, 2012. Pengaruh Kenerja Lingkungan Terhadap Corporate Financial Performance Dengan CSR Sebagai Variabel Intervening. http://eprints.undip.ac.id/35522

Sembiring, 2005. Karateristik Perusahaan dan Pengungkapan Tanggung Jawab Sosial Studi Empiris Pada Perusahaan Yang Tercatat Pada Bursa Efek Jakarta. Simposium Nasional Akuntansi 8

Suranto, Darsono, dan Siti Mutimah. 2006. Pengaruh Environmental Performance Terhadap Environmental Disclosure dan Economic Performance (Studi Empiris Pada Perusahaan 
Manufaktur Yang Terdaftar Di Bursa Efek Jakarta Priode 2001-2004). SNA IX Padang. 2326 Agustus

Triani, RR. 2010. Analisis Hubungan Antara Kinerja Ekomomi dan Kinerja Lingkungan dengan Alokasi Dana CSR Pada Perusahaan Ekstraktif. http://eprints.undip.ac.id/22701

Wardhani, Saskia Rahma. 2011. Hubungan Antara Karakteristik GCG dan Pengungkapan Tanggung Jawab Sosial Pada Sektor Finansial. http://eprints.undip.ac.id/29488/1/skripsi012

Yamin, Sofyan dan Kurniawan Heri. 2009. Structural Equation Modeling. Jakarta:SalembaInfotek. 